\title{
Pelatihan modifikasi model pembelajaran bagi guru SD se-Kecamatan Kahu
}

\author{
A.M. Irfan Taufan Asfar ${ }^{1}$, A.M. Iqbal Akbar Asfar ${ }^{2}$ Cheriani $^{3}$ \\ ${ }^{1,3}$ STKIP Muhammadiyah Bone \\ ${ }^{2}$ Fakultas Teknik, Politeknik Negeri Ujungpandang
}

\begin{abstract}
This community partnership program (PPM) aims to improve teacher professionalism through modification of the lea rning model. Improving learning practices is an alternative for the development of quality of learning that is oriented to wards the benefit of students. The method used in community partnership activities with resembles a ToT (trainer of trainer) form by collaborative-participatory dialogic a pproach includes in-house tra ining (lectures, questions and answers, discussions) for the deliv ery of material, direct practice for making modifications to learning models, testing, modeling modification practices. Supervision and visits to en sure the running of training results and to get support from resources in the continued implementation of im proving the quality of lea rning. The training participants in the community partnership program activities included 15 participants from several elementary school teachers in Kahu Subdistrict and a lso involved students as teacher assistants in m odif ying the learning model. The results achieved are knowledge partners a bout learning models, partners are a ble to m odify learning models according to teaching materials and cla ss situations that a re innovative, interesting and fun.
\end{abstract}

Key words: modification, learning model, innovative, collaborative-participatory

\section{PENDAHULUAN}

Lokasi Kecamatan Kahu Kabupaten Bone, sekitar $99 \mathrm{~km}$ dari ibukota kabupaten Bone Sekolah Dasar yang ada di Kecamatan Kahu sebanyak 38 sekolah. Lokasi sekolah-sekolah tersebut, sebagian besar terletak di daerah pedesaan sehingga kegiatan Pelatihan di bidang pendidikan yang dilakukan sangat jarang sampai ke wilayah-wilayah tersebut. Lokasi-lokasi sekolah yang sebagian besar terletak pada daerah yang agak terpencil mengakibatkan para guru jarang terlibat dalam kegiatan-kegiatan ilmiah yang dilakukan oleh Perguruan Tinggi. Sebagai dampaknya pengetahuan dan pemahaman para guru di wilayah ini masih kurang terkait dengan perangkat pembelajaran ataupun inovasi-inovasi kegiatan pembelajaran lainnya.

Dari hasil observasi awal beberapa SD di kecamatan Kahu Kabupaten Bone, guru mengeluhkan persoalan susahnya menjadikan materi pembelajaran matematika bertahan di ingatan siswa. Berbagai model pembelajaran yang telah diterapkan guru masih belum mampu memberikan kontribusi terhadap retensi daya ing at siswa dalam pembelajaran. Proses pembelajaran yang berlangsung dimana guru dalam prosesnya memberikan pembelajaran yang hanya merangsang siswa untuk menggunakan setengah kemampuan otaknya yaitu otak kiri saja sehingga prestasi belajar siswa tidak mencapai ketuntasan minimal. Padahal faktor model pembelajaran dianggap cukup penting, karena tidak hanya meningkatkan hasil belajar siswa tetapi juga berperan dalam menentukan keaktifan siswa (Reinita \& Hidayat, 2018). Guru sebagai pilar pendidikan mempunyai peranan besar dalam mendorong, membimbing dan memberi fasilitas belajar bagi siswa (Slameto, 2010), karena suksesnya penyelanggaraan pendidikan tidak terlepas dari perana dan dedikasi guru. Sehingga guru apabila tidak berkualitas, tentunya sangat mempengaruhi dunia pendidikan, untuk menghasilkan siswa yang berkualitas (Asfar \& Asfar, 2019)

Berdasarkan analisis situasi dapat teridentifikasi beberapa permasalahan yang dihadapi oleh mitra, yaitu:

a. Guru dalam mempraktekkan model pembelajaran terkendala dalam memadukan model pembelajaran dengan materi ajar, yang biasanya 
dirasakan kurang maksimal dan kadang dirasakan dipakasakan.

b. Guru masih kurang memahami dan mengembangkan ataupun mengubah model pembelajaran agar sesuai dengan materi ajar dan situasi kelas.

c. Pengetahuan mengembangkan perangkat pembelajaran yang inovatif bagi guru masih rendah sehingga guru masih kesulitan mengembangkan ataupun memodifikasi perangkat pembelajaran yang sesuai dengan kondisi kelas. Hal ini disebabkan guru jarang mengikuti kegiatan-kegiatan ilmiah terkait pengembangan model maupun perangkat pembelajaran.

Banyaknya model-model pembelajaran yang sekarang berkembang belum tentu akan cocok diterapkan berbagai materi pelajaran, oleh karena itu diperlukan usaha agar model pembelajaran yang akan digunakan disesuaikan dengan lokasi, situasi dan karaktersitik siswa yang akan diajar. Keterampilan menggunakan berbagai variasi model-model pembelajaran merupakan keterampilan yang wajib dikuasai oleh guru karena dapat menarik dan melibatkan siswa secara aktif dalam belajar. Pemilihan model pembelajaran mempertimbangkan aspek efektifitas dan relevansinya dengan materu yang disampaikan (Hia, Sumarni \& Armiati, 2016). Maka diperlukan kompetensi dalam mengubah, merancang serta menerapkan yang dikenal dengan modifikasi model pembelajaran. Model pembelajaran merupakan bentuk pembelajaran yang tergambar dari awal sampai akhir pembelajaran yang memiliki strategi, pendekatan, metode, teknik dan taktik yang disesuaikan oleh guru (Madjid, 2013). Mengingat pentingnya kompetensi ini sebagai bentuk keterampilan yang harus dimiliki oleh seorang pendidikan dalam membelajarkan materinya agar mampu dipahami oleh peserta didik. Oleh karena itu, diperlukan rambu-rambu yang bisa memfasilitasi guru secara individual maupun kelompok dan mengembangkan serta melaksanakan pembelajaran berbagai variasi model untuk muatan dan/atau mata pelajaran ynag diampunya (Asfar \&
Asfar, 2016). Atas dasar hal tersebut tim pen gabdi melakukan pengabdian kepada guru-guru seKecamatan Kahu agar memiliki kompetensi dalam menerapkan model pembelajaran di dalam kelas sehingga proses knowledge transfer berhasil dilaksanakan sebagai tujuan pembelajaran.

\section{METODE YANG DIGUNAKAN}

Metode kegiatan yang akan digunakan dalam kegiatan pelatihan ini lebih menyerupai bentuk ToT (traine of trainer) sebagai berikut:

a. Pelatihan, metode ini dimaksudkan untuk menyajikan materi tentang landasan dan rasional Modifikasi Model Pembelajaran dan analisis masalah pembelajaran.

b. Tanya jawab, untuk memberikan kesempatan bertanya kepada peserta pelatihan terhadap materi terkait analisis masalah pembelajaran dan unsur-unsur model yang akan dirancanag atau dimodifikasi.

c. Pelatihan dan supervisi penyusunan modifikasi model pembelajaran.

d. Tugas, dimaksudkan untuk megetahui sejauhmana hasil pelatihan ini dapat dipahami oleh peserta, dan diujudkan dalam proposal sesuai kondisi dan hasil analisis masalah pembelajaran.

e. Diskusi, untuk membahas rencana tindaklanjut penyebarluasan dan implementasi di sekolah masing-masing.

f. Monitoring dan pendampingan.

\section{PELAKSANAAN DAN HASIL KEGIATAN}

Hasil kegiatan PPM ini berupa proposal rancangan modifikasi model pembelajaran yang dilakukan oleh peserta pelatihan sebanyak 15 orang. Dalam proses penyusunan proposal pelatihan peserta didampingi oleh tim PPM. Proses administrasi dimulai dari surat tugas dari LPPM STKIP Muhammadiyah Bone dari tanggal 1 November sampai 30 Desember 2018. Kegiatan ini diawali dengan proses persuratan dan komunikasi serta izin dari lembaga/instasi terkait dan pelaksanaan Pelatihan dilaksanakan pada Sabtu 
tanggal 23 -24 November 2018 di Aula Kampus 3 STKIP Muhammadiyah Bone, kegiatan ini diakhiri evaluasi dan monitoring hasil modifikasi pembelajaran yang dilaksanakan di dalam kelas oleh guru yang telah melakukan pelatihan, total kegiatan PPM ini kurang lebih selama 2 bulan.

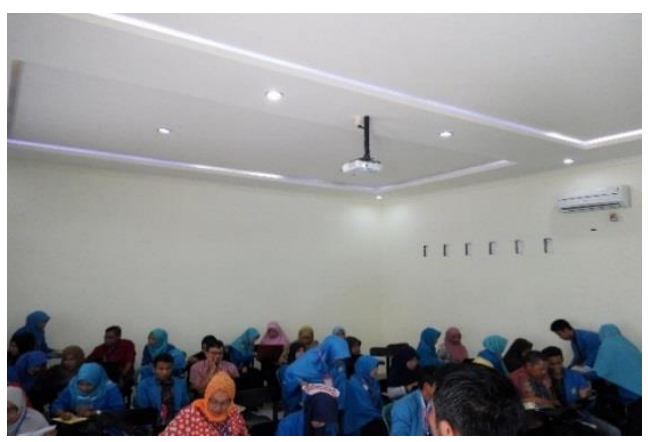

Gambar 1. Situasi pelatihan

Pada kegiatan pelatihan para guru merasakan modifikasi model pembelajaran merupakan suatu komptensi yang wajib dimiliki soerang guru untuk perbaikan kualitas pembelajaran. Guru hendaknya memiliki kemampuan yang sangat baik dalam membelajarkan siswa yang memiliki berbagai kebutuhan belajar (Darling-Hammond, 2010). Pada kenyataannya, guru-guru SD di Kecamatan Kahu masih banyak mengalami kesulitan dalam memilih model pembelajaran yang diterapkan. Ada beberapa guru telah mengetahui beberapa model pembelajaran akan tetapi setelah mereka menerapkan pada materi ajarnya tidak menunjukkan hasil yang maksimal. Oleh karena itu, pemahaman tentang model-model pembelajaran sangat penting dimiliki oleh guru karena siswa yang belajar dengan guru yang terbaik akan berdampak dengan kinerja pembelajaran akan semakin baik pula.

Kualitas guru dapat terlihat dari kualitas pembelajaran di kelas dan luar kelas. Pelatihan dan pendampingan modifikasi model pembelajaran memebrikan arahan kepada guru dalam mengembangkan dan merancang sendiri model pembelajaran yang akan digunakan di dalam kelas.

Alasannya karena tidak semua model pembelajaran cocok digunakan pada situasi, karaktersistik serta materi ajar.
Banyaknya guru masih merasa kesulitan dalam memilih model pembelajaran yang tepat sehingga kegiatan ini memberikan antusiasme guru. Kegiatan ini juga diapresiasi oleh UPTD Kecamatan Kahu yang menyempatkan waktunya beserta beberapa pengawas dalam meninjau pelaksanaan kegiatan.

Dalam implementasinya memang kesan pragmatis selelu muncul pada pihak guru namun pembahasan dan diskusi menjadi menarik manakala menyangkut situasi riil pembelajaran. Terlihat ketika model-model pembelajaran yang akan dimodifikasi para guru masih kesulitan menentukan startegi, metode ataupun pendekatan bahkan model yang tepat karena kesulitan pemahaman dalam menganalisis masalah pembelajaran, menentukan jenis tindakan menurut komponen pembelajaran, model-model pembelajaran yang sesuai, dan evaluasinya.

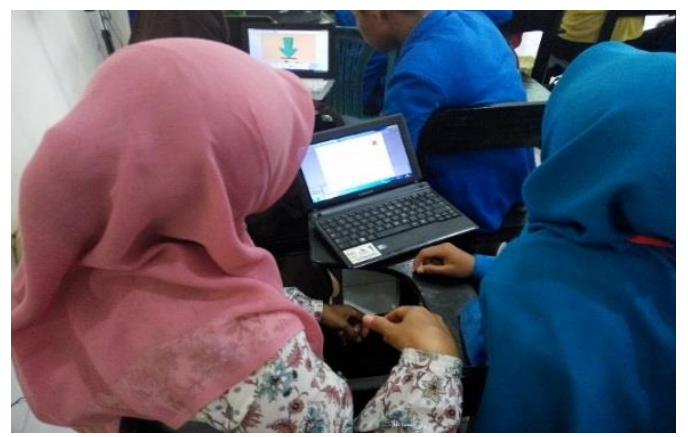

Gambar 2. Proses pelatihan didampingi mahasis wa dalam memudahkan dan memfasilitasi kendala teknis yang dihadapi guru selama pelatihan

Hal yang sangat menarik karena dengan penglaman para guru sangat mengenali persoalan pembelajaran di kelasnya, namun karena ketidakpahaman dalam memahami bahkan memodifikasi model sehingga para guru kembali pda pola megajar yang lama yaitu berpusat pada guru. Sementara dalam menentukan model pembelajaran masih kesulitan memahami sintaks pembelajaran sebagai sistem dengan unsur-unsur model pada umumnya sehingga sulit menentukan langkah dalam menggabungkan model secara spesifik. 
Hasil analisis masalah sebagian guru sebenarnya berada pada persoalan penggunaan model-model pembelajaran yang tepat, bagaimana merancang model yang cocok di dalam kelas dan sistem evaluasi. Hanya saja diperlukan wawasan guru tentang beragam jenis model, sintaks dan cara evaluasinya terlebih dahulu. Dari segi penerapan strategi atau model yang digunakan sehari-hari nampak pemahaman metode lebih banyak berasal dari kebiasaan yang digunakan, mengikuti sifat dari mata pelajaran misalnya sains karena adanya alat peraga IPA mendorong penggunaan eksperimen namun belum menunjukan penguasan dengan baik beberapa metode alternatif yang sebenarnya bukan barang baru lagi. Ceramah, diskusi, inkuiri, penugasan (resitasi), tanya jawab dikenal namun penguasan metode dengan baik masih kurang. Dari metode yang dikenal ceramah, tanya jawab dan penugasan paling sering digunakan.

Pada sisi sistem evaluasi sebagian besar masih menggunakan evaluasi berbasis kognitif dengan jenjang kemampuan kognitif rendah karena faktor kebiasaan. Penilaian dalam bentuk tes masih mendominasi sehingga ketika akan menguji cobakan cara penilaian baru keterbatasan wawasan menjadi faktor penghambat yang menentukan. Guru mengenal sistem penilaian portofolio namun tidak memahami betul esesensinya sehingga ketika menerapkan masih kesulitan.

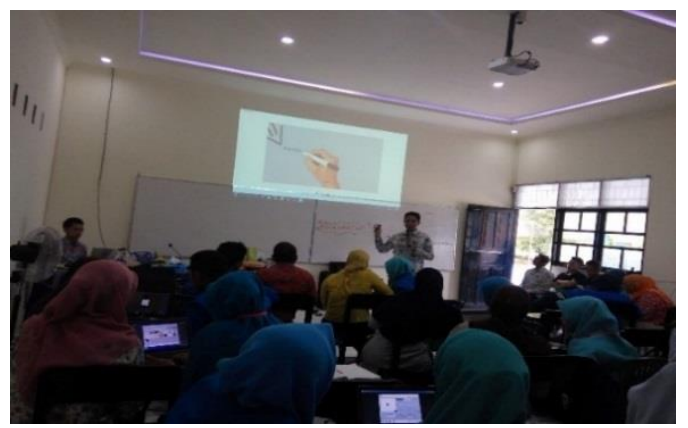

Gambar 3. Pemberian materi dan tanya jawab serta diskusi

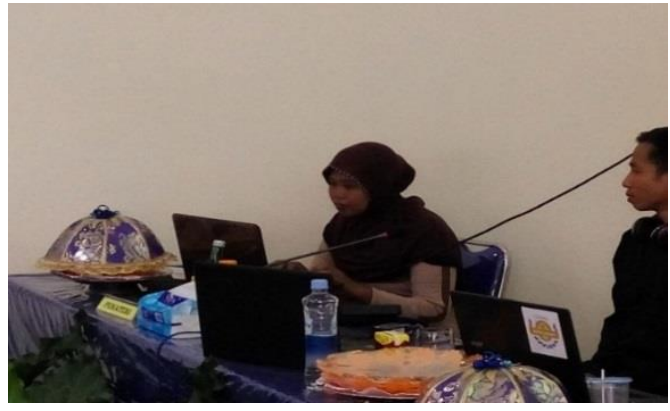

Gambar 4. Salah satu peserta memaparkan hasil rancangan modifikasi model pembelajaran

Atas dasar hal tersebut terlihat bahwa dalam melaksanakan modifikasi model pembelajaran guru ada kebutuhan penguasaan akan metode, media, sistem evaluasi dan komponen pembelajaran lainnya. Hal ini bisa direvitalisasi melalui pengembangan minat baca guru serta membudayakan adanya budaya menulis. Guru hendaknya diberikan kebebasan berekspresi dan beraktualisasi diri. Sistem apresiasi pemerintah melalui penawas hendaknya lebih memberikan point bagi aktifitas guru melalui forum-forum seperti KKG, MGMP, dan forum ilmiah lain sebagai bentuk aktifitas akademik yang mendukung pengembangan profesionalisme bukan sekedar tuntutan kinerja administratif.

Setelah proses pelatihan maka tim PPM akan melakukan evaluasi dan monitoring hasil pelatihan dalam bentuk evaluasi di lapangan. Hasil implementasi menunjukkan beberapa guru telah mampu menerapkan hasil rancangan modelnya walupun masih ada kendala dari segi sarana dan prasarana tetapi hal tersebut tidak menyurutkan guru untuk menghadirkan proses pembelajaran yang inovatif, bermakna dan menyenangkan pada siswa. Kegiatan lain yang diminta tindaklanjuti oleh para guru adalah proses penulisan karya ilmiah. Hal ini sebagai evaluasi bagi tim PPM dalam memberikan program pelatihan berikutnya sehingga pelatihan dan pendampingan ini tidak terputus tetapi berkelanjutan serta memberikan stimulus dalam mensinergikan tim dengan guruguru dalam rangkan intensitas interaksi dan berbagi wawasan dengan guru. 


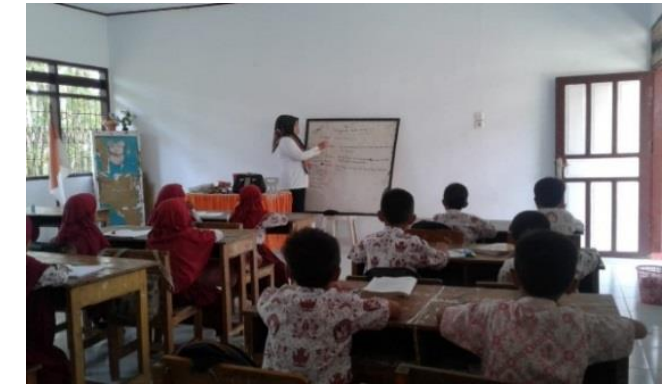

Gambar 5. Proses pendampingan guru dalam menerapkan modifikasi model pembelajaran

Dari monitoring dan evaluasi tim juga menemukan fakta bahwa masih banyak guru-guru yang ingin mengikuti program PPM khususnya guruguru muda. Guru-guru muda ini memiliki motivasi yang tinggi, sehingga juga menjadi bahan rujukan nanti pada kegiatan program sejenis untuk menambah kuota peserta kegiatan PPM. Tim menyadari hendaknya motivasi guru-guru muda ini selalau dijaga dengan memberikan iklim akademik yang kondusif dan penuh penghargaan terhadap kinerja akademik guru sehingga harapannya dipundak merekalah bagi generasi muda guru-guru ini digantungkan demi kemajuan pendidikan di Indonesia.

\section{KESIMPULAN}

Hasil pelaksanaan kemitraan masyarakat dapat ditarik kesimpulan:

a. Guru memiliki keterampilan dalam merancang pembelajaran.

b. Guru memahami dan mampu mengembangkan ataupun mengubah model pembelajaran agar sesuai dengan materi ajar dan situasi kelas.

c. Guru memiliki terampil dalam menerapkan model hasil modifikasi perangkat pembelajaran yang inovatif, menarik dan menyenangkan.

\section{UCAPAN TERIMA KASIH}

Ucapan terima kasih disampaikan kepada Ketua STKIP Muhammadiyah Bone atas arahan dan pembinaanya selama proses kegiatan Pengabdian Masyarakat berlangsung. Demikian pula ucapan terima kasih disampaikan kepada Kepala Lembaga Pengabdian Kepada Masyarakat (LPPM) STKIP Muhammadiyah Bone dan Pemerintah Kabupaten Bone Provinsi Sulawesi Selatan Khususnya UPTD Kecamatan Kahu yang memfasilitasi, memonitoring dan mengevaluasi sampai berakhirnya kegiatan pelatihan serta pendampingan.

\section{DAFTAR PUSTAKA}

Asfar, AMIT., Asfar, AMIA. 2016. Analisis Kurikulum 2013. Researchgate Method, 1-99. doi: 10.13140/RG.2.2. 31650.07365 .

Asfar, AMIT., Asfar, AMIA. 2019. Hakikat, Arti Dan Krisis Pendidikan: Perspektif Proses Pendidikan. Researhcgate Article 1-16. https://www.researchgate.net/publication/ 331225030 .

Darling-Hammond, L. 2010. Recognizing and Developing Effetive Teaching: What Policy Makers Should Know and Do, Policy Brief, 1-12. https:// www.nea.org/assets/docs/ HE/Effective_Teaching_-_Linda_Darling-Hammond.pdf.

Hia, Y.,Dewi,. Sumarni, \& Armiati. 2016. Pelatihan Metode Pembelajaran Inovatif Untuk Meningkatkan Profesionalisme Guru SMA. Jurnal Pelangi, 8 (2), 243 249.

Majid, A. 2013. Strategi Pembelajaran. Bandung: PT Remaja Rosdakarya.

Reinita, Hidayat, M Taufik. 2018. Pelatihan Model Pembelajaran Kooperatif Tipe Listening Team Bagi Guru Sekolah Dasar Kecamatan Tanjung Mutiara Kabupaten Agam. Prosiding ICCE Universitas Muhammadiyah Surakarta, 1-7.

Slameto. 2010. Belajar dan Faktor yang mempengaruhinya. Jakarta: Rineka. Cipta. 